FONTES E ARQUIVOS 



\title{
A catalogação de acórdãos e processos individuais do Tribunal Regional do Trabalho do Rio de Janeiro
}

\author{
Larissa Rosa Côrrea* \\ Alexander Englander** \\ João Roberto Oliveira Nunes, \\ Marcelo Barros e Edna Mendes***
}

Recentemente, os tribunais trabalhistas brasileiros passaram a se preocupar com a política de gestão documental dos seus acervos. Diante da prática de eliminação dos processos trabalhistas, muitos tribunais passaram a realizar ações de preservação documental e de difusão da memória e da história da Justiça do Trabalho. ${ }^{1}$ O tratamento dessa documentação judicial, ao mesmo tempo em que abriu enorme leque de possibilidades de pesquisa sobre o mundo do trabalho e da história política e social, significou também um novo desafio para os arquivistas e historiadores. Afinal, como organizar as informações presentes nos processos individuais e coletivos, de forma que ela se torne acessível a qualquer pesquisador? Como lembrou Antonio Montenegro, "é de conhecimento público a importância da preservação da memória de uma sociedade, pois apenas por meio dela é possível não só aprender com o passado, mas construir outras formas de entendimento do presente". ${ }^{2}$

Nesse sentido, as fontes judiciais do TRT da $1 .{ }^{a}$ Região, assim como as dos demais tribunais trabalhistas, revelam-se fundamentais para a compreensão de importantes processos históricos, políticos, econômicos e sociais do estado do Rio de Janeiro e do país. Desde a sua instalação em 1941, a Justiça do Trabalho tornouse palco de numerosos conflitos e negociações trabalhistas, resultado das ações e experiências da classe trabalhadora e dos empregadores. Esses conflitos, uma vez encaminhados à Justiça do Trabalho, passaram a adquirir diferentes significados

* Doutora em História Social pela Unicamp, correspondente do Instituto Internacional de História Social de Amsterdam. Email: larissarosacorrea@hotmail.com

** Doutorando em Sociologia pelo IESP. Email: alexcoueng@gmail.com

***Funcionários da Seção de Gestão de Memorial do TRT $1^{\text {a }}$ Região, pós- graduados em História e Sociologia. Contato: secmei@trt1.jus.br

1 Exemplos nesse sentido podem ser observados no TRT $4 .{ }^{\text {a }}$ Região, no Rio Grande do Sul, no TRT da $6 .{ }^{\text {a }}$ Região, em Pernambuco, no TRT 3. ${ }^{a}$ Região, em Minas Gerais. Ver: CAIXETA, Maria Cristina D.; DINIZ, Ana Maria M.M.; CUNHA, Maria Aparecida C.; CAMPANTE, Rubens G. (orgs.). IV Encontro Nacional da Memória da Justiça do Trabalho. Cidadania: o trabalho da memória. São Paulo: LTr, 2010.

2 MONTENEGRO, Antonio. "História e trabalho - o TRT 6. ${ }^{\mathrm{a}}$ região e a UFPE: memória e pesquisa historiográfica”. In: CAIXETA; DINIZ. Idem, p. 48. 
ao longo das variadas conjunturas políticas, sociais e econômicas. Cabe agora aos pesquisadores interessados em compreender as relações entre o capital e o trabalho analisar a presença, a experiência, as iniciativas, bem como os valores e as estratégias dos trabalhadores livres e industriais ao longo do século XX nas fontes disponíveis da Justiça do Trabalho. ${ }^{3}$

Ciente da importância da preservação das fontes judiciais para o conhecimento histórico, a Seção de Gestão de Memorial do TRT da $1 .{ }^{a}$ Região elaborou o projeto de catalogação dos acórdãos e processos trabalhistas, oriundos do estado do Rio de Janeiro e demais regiões antes pertencentes a esse tribunal. ${ }^{4} \mathrm{O}$ projeto Mentoring, iniciado em janeiro de 2012, dedicou-se à organização das informações presentes em parte da documentação de caráter permanente do TRT/RJ. Trata-se, mais precisamente, de cento e cinquenta processos autuados, contendo reclamatórias individuais, até o ano de 1990, arquivados durante o período 2000/2001 e dois mil e quinhentos acórdãos lavrados desde o período de instalação da Justiça do Trabalho, que tratam de dissídios coletivos e individuais.

Por meio das fontes judiciais é possível analisar, de modo quantitativo e qualitativo, diversas temáticas referentes ao mundo do trabalho, como os conflitos e negociações entre empregadores e trabalhadores, as relações de trabalho no chão de fábrica, os aspectos do processo de industrialização, as relações entre os trabalhadores, bem como a construção e a conquista das leis e direitos. Os autos permitem, ainda, conhecer o pensamento e a atuação dos magistrados, realizar análises comparativas entre os tribunais, verificando o perfil dos juízes em determinadas regiões, entre outros desdobramentos temáticos. ${ }^{5}$ Ademais, por meio dos acórdãos oriundos dos processos individuais e coletivos, podemos observar a criação dos direitos e da jurisprudência trabalhista. ${ }^{6} \mathrm{O}$ acompanhamento das decisões judiciais neles presente revela o processo de formação do sistema jurídico trabalhista, construído a partir da decisão dos conflitos encaminhados pelos trabalhadores e empregadores.

Como observou Clarice Speranza, o número de estudos que utilizam os processos trabalhistas como fontes de pesquisa histórica é crescente, da mesma forma que aumentam as investigações sobre as diferentes maneiras em que a legislação brasileira afetou e foi afetada pela experiência dos trabalhadores. Não obstante, alguns pesquisadores têm buscado compreender as normas trabalhistas, desvelando aspectos que haviam sido negligenciados nas interpretações anteriores. ${ }^{7}$

\section{O trabalho de catalogação dos acórdãos}

Ao selecionar os acórdãos produzidos durante as décadas de 1940 e 1960, foi dada prioridade ao conjunto documental mais antigo. Tal opção foi justificada

3 Embora o uso das fontes da Justiça do Trabalho seja ainda recente, podemos dizer que há disponível uma bibliografia considerável sobre o uso e sobre a análise das fontes judiciais trabalhistas. Ver exemplos em: NEGRO, Antonio Luigi. "O que a Justiça do Trabalho não queimou”. POLITEIA: Hist. e Soc. Vitória da Conquista, v. 6, n. 1, 2006, p. 193-209.

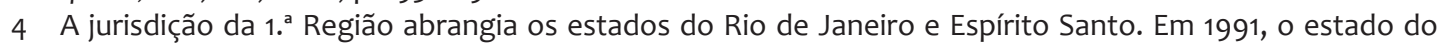
Espírito Santo se desmembrou e se tornou a $17 .{ }^{\text {a }}$ Região.

5 CORRÊA, Larissa Rosa. A tessitura dos direitos. Patrões e empregados na Justiça do Trabalho, 1953-1964. São Paulo: LTr, 2011.

6 No caso do TRT do Rio de Janeiro, os acórdãos adquirem extrema importância para os estudos do mundo do trabalho e da justiça trabalhista na região, uma vez que os dissídios coletivos e individuais referentes aos anos de 1940 e 1970 foram descartados.

7 SPERANZA, Clarice G. "Cavando direitos. As leis trabalhistas e os conflitos entre trabalhadores e patrões nas minas do Rio Grande do Sul nos anos 40 e 50". Tese de doutorado. Porto Alegre: Programa de Pós-Graduação em História - UFRGS, 2012, p. 29. 
não apenas pela fragilidade do suporte, mas também por serem escassas as fontes judiciais que retratam os conflitos trabalhistas, sobretudo os individuais, nesse período. O recorte temporal escolhido para a seleção da amostra pautou-se nos eventos considerados mais significativos da história do movimento operário no Rio de Janeiro, da Justiça do Trabalho e dos acontecimentos históricos nacionais e internacionais. Assim, foram selecionados os seguintes anos:

- 1941: ano de instalação e funcionamento da Justiça do Trabalho, período em que Alexandre Marcondes Filho assumiu o Ministério do Trabalho. Sua gestão foi marcada pela elaboração da Consolidação das Leis do Trabalho (CLT), por campanhas de sindicalização, programas de construção de vilas operárias e pela construção da imagem de Getúlio como defensor dos interesses dos trabalhadores. ${ }^{8}$ É o período de consolidação do sistema corporativista das relações de trabalho, de organização dos tribunais trabalhistas e de composição dos direitos. Ano também de criação da Companhia Siderúrgica Nacional (CSN), situada no município de Volta Redonda, no Rio de Janeiro, conhecida como a maior siderúrgica do país.

Ao se estabelecer como órgão próprio para conciliar e julgar os conflitos entre empregados e patrões nas relações de trabalho, a Justiça do Trabalho revestiu-se de três características principais: 1) tinha natureza especializada, uma vez que se limitava às relações de emprego/trabalho; 2) caráter paritário e representativo, incorporando em seus quadros os chamados vogais ou juízes classistas, representantes sindicais dos empregados e empregadores; 3) caráter administrativo, pois era vinculada ao Ministério do Trabalho, Indústria e Comércio e atrelada ao Poder Executivo. ${ }^{9}$

- 1947: os acórdãos produzidos neste ano permitem observar as decisões judiciais apresentadas após a realização de uma série de mudanças legais aprovadas no governo Dutra, como o decreto-lei n.9.070, de 15 de março de 1946, que restringiu e regulamentou o direito de greve. Em setembro desse mesmo ano, foi lançado o decreto n.9.797, que transferiu a Justiça do Trabalho para o Poder Judiciário, como justiça autônoma e especial. Os Conselhos Regionais tornaram-se Tribunais Regionais e o Conselho Nacional foi substituído pelo Tribunal Superior do Trabalho. Na sequência, foi promulgada a Constituição de 1946. O governo Dutra foi marcado por uma série de conflitos trabalhistas e de forte mobilização operária, tendo sido registradas setenta e sete paralisações somente nos três primeiros meses de 1946. Desse modo, seria interessante analisar se essas manifestações tiveram reflexo no TRT do Rio de Janeiro e como o tribunal tratou das demandas encaminhadas pelos trabalhadores.

Segundo Fernando Teixeira da Silva, antes de 1946, a CLT não conferia aos sindicatos competência para celebrar contrato coletivo como representante legal de toda a categoria, sendo a abrangência dos acordos limitada apenas aos trabalhadores sindicalizados. A sentença judicial deveria ter caráter normativo, ou seja, tinha o poder de criar normas e estipular condições de trabalho conforme a solução dos dissídios coletivos. Essa característica permitia aos juízes trabalhistas no Brasil a criação de novos direitos. Com a Constituição de 1946, os direitos

8 A contextualização dos anos selecionados para a catalogação teve como base a linha do tempo publicada no livro: GOMES, Angela de Castro. Ministério do Trabalho: uma história vivida e contada. Rio de Janeiro: Cpdoc, 2007.

9 Em 1946, a jurisdição do TRT da 1. ${ }^{a}$ Região abrangia, além do Distrito Federal, o antigo estado do Rio de Janeiro e do Espírito Santo. O primeiro grau de jurisdição era composto por Juntas de Conciliação e Julgamento, distribuídas da seguinte forma: nove na capital e uma nos municípios de Niterói, Campos, Petrópolis, Cachoeiro do Itapemirim e Vitória. Ver: "Memória institucional - história e cronologia" do TRT 1. ${ }^{\text {a }}$ Região. Disponível em: http://www.trt1.jus.br/breve-historico-e-cronologia. Acesso em 8 de julho de 2013. 
conquistados na Justiça do Trabalho passaram a ser estendidos para todos os trabalhadores de uma categoria ou ramo produtivo, independentemente de sua sindicalização. ${ }^{10}$

- 1959: Após a Greve Nacional dos Marítimos, o novo ministro do Trabalho, Fernando Nóbrega, procurou impedir a ocorrência de paralisações duradouras e realizou acordos com os presidentes das confederações das diferentes categorias de trabalhadores. Esse período foi caracterizado pela intensa atividade sindical proporcionada pela conjuntura política de razoável estabilidade democrática, bem como pela construção de direitos e de melhor remuneração do trabalho, que só vai ser estancado com o golpe civil-militar de $1964 .{ }^{11}$

- 1963: ano fundamental para a compreensão do período que antecedeu a instauração do regime ditatorial, conjuntura marcada pela ocorrência de grandes greves gerais em todo o país. Nesse período seria interessante questionar de que forma as tensões e os conflitos políticos de âmbito nacional e regional, marcados pela pressão do movimento operário e dos setores conservadores civil e militar, influenciaram as decisões judiciais no TRT do Rio de Janeiro.

Vale lembrar que, um ano antes, o presidente João Goulart havia anunciado durante um discurso realizado na cidade de Volta Redonda a intenção de promover as tão reivindicadas reformas de base. Não menos importante foi a aprovação do $13 .^{\circ}$ salário, pela lei 4.090 , assinada em julho de 1962 . Antes, o benefício era considerado uma gratificação fornecida como mera liberalidade dos patrões. Os empregados ficavam dependentes da boa vontade dos empregadores no tocante à concessão do abono natalino. Nesse sentido, caberia analisar como o TRT recebeu os pedidos de pagamento do $13 .^{\circ}$ salário. Além do abono natalino, a conjuntura é marcada pela criação do Comando Geral dos Trabalhadores (CGT). Considerado ilegal e não reconhecido pelo Ministério do Trabalho, o CGT reunia diversos órgãos intersindicais regionais.

É possível que os acórdãos produzidos em 1963 possam refletir os eventos ocorridos no ano anterior, incluindo as diversas greves eclodidas, entre elas a dos ferroviários, portuários, aeroviários, marítimos e operários navais. No Ministério do Trabalho e Previdência Social, Amauri Silva tornou-se o novo ministro. Durante sua gestão, o número de sindicatos de trabalhadores rurais passou de cento e cinquenta para mil cento e cinquenta, e novas federações sindicais regionais de trabalhadores foram organizadas.

- 1968: a lei n. ${ }^{\circ} 5.541$, assinada em junho de 1968, introduziu a mudança no cálculo dos reajustes salariais fixados pela política econômica. O governo, embora tivesse reconhecido que os reajustes salariais anteriores haviam sido menores do que a inflação, recrudesceu a política de arrocho salarial. Com o recrudescimento da repressão política pelo regime militar, o que muda no funcionamento da Justiça do Trabalho?

\section{Os acórdãos como fontes de pesquisa}

Buscando sistematizar as informações constantes nos acórdãos, procuramos fazer uma leitura a contrapelo, a fim de resgatar a origem do conflito. Acontece que, com exceção dos dissídios coletivos, os acórdãos elaborados nos tribunais regionais do trabalho são consequência de recursos, instaurados por parte dos

10 SILVA, Fernando Teixeira. "Justiça do Trabalho Brasileira e Magistratura del Lavoro Italiana: apontamentos comparativos". In: CAIXETA; DINIZ, op.cit., p. 74.

11 MATTOS, Marcelo Badaró. “Greves, sindicatos e repressão policial no Rio de Janeiro (1954-1964)". Revista Brasileira de História, v.24, n.47, 2004, p. 241-270. 
patrões ou dos empregados. ${ }^{12}$ Ao identificar o processo, observamos que o relator indicava apenas quem era o recorrente da ação. Se tivéssemos considerado apenas esse dado, teríamos perdido uma das informações principais do processo: o autor da ação. Nesse sentido, mesmo sabendo que os acórdãos representam partes resumidas do processo, buscamos analisá-lo de forma mais ampla, de modo a compreendê-lo em sua totalidade, com o objetivo de recuperar informações sobre a origem do conflito e extrair o maior número de informações possível.

Vale lembrar que os acórdãos apresentam uma versão resumida do processo. Sua narrativa varia conforme o seu autor, no caso, o relator, não abrangendo toda a extensão e discussão em que se pautou o julgado, mas apenas os principais pontos da discussão. Em relação ao período analisado, é importante atentar para as diferenças cronológicas entre a ocorrência do conflito e a publicação do acórdão. Uma ação judicial de caráter individual ou coletivo poderia tramitar na Justiça do Trabalho durante seis meses, um ano ou mais, dependendo do conflito julgado e do número de processos impetrados nos tribunais. ${ }^{13}$ Ademais, percebese que na primeira década de funcionamento da Justiça do Trabalho o processo era julgado no mesmo ano em que as ações eram instauradas. Já nas décadas de 1950 e 1960, a distância entre a apresentação da ação e a sentença foi maior a cada ano. Esse período entre a entrada do processo e sua conclusão é fundamental para contextualizar os motivos que levaram o autor da ação a apresentar sua reclamação e o contexto em que o conflito fora julgado.

Em geral, muitas informações aparecem nos acórdãos de modo inconstante, uma vez que o seu conteúdo variava conforme o relator. No entanto, alguns dados apresentam-se de maneira regular e nos permitem traçar um retrato da instituição a partir das seguintes questões:

- Quais grupos instauravam mais processos nas Juntas de Conciliação e Julgamento: empregados ou empregadores?;

- Homens ou mulheres? (aqui também é possível comparar gênero por categorias profissionais e por data);

- Processos instaurados por cidade;

- Análise do número de dissídios individuais, coletivos e homologações por ano no TRT da $1 .{ }^{a}$ região;

- Ideia geral dos tipos de demandas, pois não é possível saber se o relator reproduzia a lista completa de reclamações apresentadas no processo;

- Análise das decisões dos tribunais de $10^{\text {a }}$ e $2 .^{a}$ instâncias. É possível saber se os juízes eram mais favoráveis ou não às reclamações impetradas por trabalhadores e empregadores;

- Quem entrava mais com recursos: patrões ou empregados?

- Pesquisa pelo nome do relator;

- Pesquisa por ano, empresa, cidade e por categoria profissional.

A base de dados permite ainda cruzar as demandas com as categorias profissionais e analisá-las por ano e/ou cidade. Além disso, o conjunto de palavraschave, elaboradas para cada acórdão e normatizadas pelo uso do vocabulário controlado, sugere entradas de pesquisa para o consulente, além de uma síntese

12 Trata-se de recursos instaurados após os resultados das reclamatórias julgadas nas Juntas de Conciliação e Julgamento.

13 Essa afirmação não tem comprovação empírica. Ainda é preciso realizar um estudo quantitativo minucioso sobre a média de tempo de duração de um processo trabalhista individual. 
do conflito trabalhista. Exemplo de palavras-chave: categoria do trabalhador + demanda + prática de comportamento do empregado ou do empregador + contextualização (custo de vida, política salarial, por exemplo).

\section{A catalogação dos processos individuais}

Para a seleção da amostra de processos individuais foram selecionados cinquenta e cinco autos da Vara de Nova Iguaçu (de 1984 a 1990) e noventa e cinco de diferentes Varas Trabalhistas da cidade do Rio de Janeiro, entre os anos de 1978 e 1990, totalizando um conjunto de cento e cinquenta processos. ${ }^{14}$ A análise dos documentos apontou para um conjunto de questões possíveis de serem compreendidas a partir da catalogação dos processos. Uma delas é quanto tempo o reclamante esperava em média na justiça trabalhista para ter o seu direito atendido. Para isso, foi realizada uma descrição minuciosa do trâmite processual e da fase de execução dos processos. Nesse sentido, procuramos saber quais eram os passos burocráticos que o trabalhador tinha que percorrer até receber o valor de sua indenização ou dos seus direitos após a data do julgamento. Também buscamos fazer um cálculo de quanto tempo durou cada processo, considerando a data do último documento anexado nos autos ou a data de arquivamento, quando havia.

O levantamento dessas informações permite compreender os caminhos percorridos pelos trabalhadores na Justiça do Trabalho quando buscavam reivindicar seus direitos individuais. A descrição do rito judicial contribui para a análise dos diferentes significados atribuídos pelos trabalhadores ao papel desempenhado pela justiça trabalhista. Possibilita, também, observar o posicionamento dos magistrados em relação aos interesses dos trabalhadores e como empregados e empregadores utilizavam o trâmite judicial para orientar o rumo das negociações. ${ }^{15}$

Entre os mais de trinta campos preenchidos no banco de dados para cada processo, é possível encontrar uma série de informações sobre os conflitos trabalhistas. Destacam-se os dados sobre o local de trabalho e de moradia do trabalhador reclamante (cidade e bairro); nome dos advogados dos reclamantes e dos reclamados; a função do trabalhador; a duração do vínculo empregatício; os diferentes tipos de demandas; a descrição da sentença (se procedente, procedente em parte, improcedente ou arquivado); o tempo de duração do processo; o autor do recurso (empregado ou empregador); além de um resumo do conflito; do trâmite processual; e, por fim, o trâmite da execução. Nesse último item buscamos informar se o trabalhador reclamante recebeu o valor da condenação, de que forma e quando.

A sistematização desse conjunto de informações pode revelar características importantes sobre o perfil do empregado reclamante na Justiça do Trabalho. É o caso das fichas de funcionário anexadas nos processos. Nelas, podemos ter conhecimento do tipo do trabalho e da função exercida pelo trabalhador. Nos processos individuais também é possível analisar os termos do contrato de trabalho, bem como as condições da jornada de trabalho, os argumentos dos advogados, as decisões do tribunal ou o acordo estabelecido, ter acesso ao parecer do Ministério Público do Trabalho, entre outras questões.

\section{Apontamentos da amostra}

Numa primeira análise dos dados sistematizados no projeto, percebemos que os acórdãos julgados pelo Conselho Regional do Trabalho (CRT) da $1 .{ }^{a}$ Região, de

14 A partir de 1999, as Juntas de Conciliação e Julgamento passaram a ser denominadas Varas do Trabalho, conforme determinação da emenda constitucional n. 24, de 9 de dezembro desse mesmo ano.

15 CORRÊA, Larissa R. A tessitura dos direitos, op. cit., p. 102. 
1941, mostram que mais de dois terços das reclamações que chegaram ao grau de recurso foram impetradas por categorias de empregados, de forma individual, nas Juntas de Conciliação e Julgamento. ${ }^{16}$ Igualmente, informamo-nos de que naquele período, mais de $80 \%$ dos trabalhadores que entraram com ações e chegaram ao grau de recurso na Justiça do Trabalho eram homens, em sua maioria pertencentes às categorias de trabalhadores marítimos, ferroviários e os empregados da Cia Carris, Luz e Força do Rio de Janeiro.

Outra questão observada na amostra analisada sobre este momento inaugural do funcionamento da Justiça do Trabalho foi o elevado número de inquéritos impetrados pelas categorias de empregadores. Essas ações tinham o intuito de demitir por justa causa os trabalhadores detentores de estabilidade. Entre as justificativas mais comuns alegadas pelos empregadores para a demissão dos trabalhadores estáveis, encontra-se o abandono de emprego, o cometimento de falta grave por indisciplina e desídia.

Já a amostra de oitocentos e vinte e três acórdãos, referente ao primeiro semestre de 1947, é marcada por um significativo crescimento da proporção de empregados que entraram em 1. ${ }^{a}$ instância na Justiça do Trabalho em relação à quantidade de ações iniciadas pelos empregadores. Se, em 1941, 73,06\% dos processos foram iniciados pelos trabalhadores, em 1947, esses números aumentaram para 92,22\%. De modo semelhante, o número de dissídios coletivos aumentou: de apenas dois em 1941 para mais de cinquenta em 1947. Esses dados apontam para a construção do processo de institucionalização da ação coletiva dos sindicatos na Justiça do Trabalho. Tais evidências fortalecem a hipótese de que os trabalhadores se apropriaram da lei trabalhista para buscar seus direitos sejam eles rescisórios ou por melhores condições de trabalho.

Ainda sobre o uso da justiça trabalhista pelos trabalhadores, percebemos que a categoria profissional que mais se destacou nos documentos analisados de 1947 foi a de transportes e energia elétrica, com participação em cinquenta e nove acórdãos, quase todos provenientes da empresa Cia. Carris, Luz e Força do Rio de Janeiro. Além desta, outras categorias se destacaram, entre elas a de Construção Civil, com vinte e seis acórdãos, a de Alimentos, com vinte e um e de Bancários, com dezenove. Outra categoria observada nos acórdãos foi a dos trabalhadores de cassinos, que aparecem em onze casos. Os empregadores se viram pressionados a pagar verbas rescisórias por demissão sem justa causa. Tais contendas ocorreram em função da lei que, instaurada no governo Dutra, proibiu os jogos de azar no país.

Sobre os trezentos acórdãos sistematizados referentes ao ano de 1959, apesar de apresentar um maior número de dissídios individuais, percebeu-se uma quantidade considerável de dissídios coletivos. Neles, a demanda pela recuperação das "diferenças salariais" aparece como a mais comum, como mostra o conjunto de palavras-chave daquele período. Findos os contratos de trabalho, os empregados vinham buscar na Justiça do Trabalho as compensações por situações de contrato irregular que estavam em vigência durante a relação de emprego.

A Justiça do Trabalho não era apenas procurada para resolução das demandas referentes à remuneração. Não é demais lembrar que nos anos de 1950, passados mais de uma década de sua implantação, a Justiça do Trabalho encontrava-se em fase de criação de um discurso específico, diverso do enfoque contratualista e individualista da justiça comum. Relacionado a esse aspecto, notamos na documentação abordada do ano de 1959 a consolidação de alguns direitos, em

16 A amostra para o ano de 1941 abrangeu trezentos e setenta e cinco acórdãos. 
especial aos adicionais na remuneração do trabalho em condições gravosas, como o trabalho noturno, perigoso e insalubre.

No ano de 1963, observou-se maior variedade de conflitos trabalhistas encaminhados por diversas categorias de trabalhadores à Justiça do Trabalho. A maior parte das ações analisadas na amostra, composta por quinhentos e setenta e oito acórdãos, foi instaurada por trabalhadores oriundos de categorias com menor grau de organização e representação coletiva. Nesse segmento, destacaram-se os trabalhadores de bares e restaurantes, as trabalhadoras em hotéis e pensões, as arrumadeiras e lavadeiras, os empregados em estabelecimentos hípicos, rádio e até mesmo os jogadores de futebol — todos em busca de comprovação do vínculo empregatício.

Nesse período, acumularam-se os pedidos de pagamento do $13 .^{\circ}$ salário, também conhecido como gratificação de Natal, de indenização por demissão sem justa causa, de cumprimento do reajuste salarial concedido em acordo ou dissídio coletivo, além de outras reivindicações chamadas de "pequenos direitos", como o aviso-prévio e férias. Já os empregadores, de modo geral, procuraram se defender das ações trabalhistas, alegando demissões por casos de embriaguez, roubo, violência física, falta de produtividade e problemas de saúde mental.

Por fim, o conjunto de acórdãos do ano de 1968 refere-se, em sua maioria, aos dissídios individuais autuados nos primeiros anos da década de 1960, período marcado pela crise política e econômica, iniciada com a renúncia de Jânio Quadros, e também por um cenário econômico desfavorável, caracterizado pela perda do dinamismo alcançado na década anterior, pelo desemprego e pelo alto índice inflacionário. A análise dos trezentos enoventa e três acórdãos possibilitou perceber o reflexo desse cenário na vida dos trabalhadores. Chama atenção a recorrência de demandas, tais como: adicional de insalubridade, gratificação de natal (ou 13. salário) e pagamento de horas extras. Essas demandas não apenas ratificavam os direitos conquistados, como também efetivavam um acréscimo salarial, em um período de difícil negociação entre trabalhadores e patrões. A resposta dos juízes a esses pedidos, de maneira geral, foi favorável aos trabalhadores.

Outro aspecto relevante observado nos acórdãos de 1968 foram as estratégias formuladas pelos empregadores visando romper o vínculo contratual com seus empregados, em especial os ferroviários, prestes a obter o direito à estabilidade decenal — fosse na forma de demissão por justa causa ou por encaminhamento de inquérito na Justiça do Trabalho. Nesse particular, o julgamento dos juízes, no que tange à amostra analisada, nem sempre se mostrou sensível aos trabalhadores.

Recebido em 11/2012 Aprovado em 07/2013 